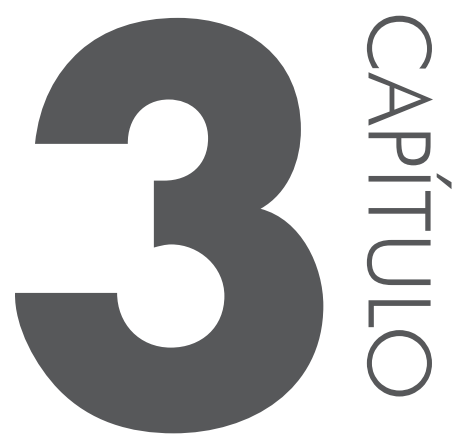

\title{
DESENVOLVIMENTO DE QUEIJO PETIT-SUISSE COM EXTRATO DE SOJA
}

Ana Paula Cristiane de Andrade Neusa Fátima Seibel

\section{INTRODUC̣ÃO}

A soja em grãos ou seus derivados têm sido estudados por pesquisadores e introduzidos gradativamente no consumo da população devido não apenas ao seu valor nutricional, mas também às suas propriedades funcionais. Essas propriedades levam a soja a ser classificada como um alimento funcional por exercer efeitos benéficos no organismo, reduzindo o risco de doenças crônicas não transmissíveis por meio das proteínas de ótimo valor biológico e das isoflavonas presentes na soja (CIABOTTI et al., 2006).

Apesar de a soja possuir efeitos benéficos ao organismo, o seu baixo consumo no Brasil está associado ao sabor, ao odor e também a hábitos alimentares. 
O sabor, retratado como amargo, adstringente e rançoso, decorrente da ação da lipoxigenase, é a principal causa limitante do consumo de soja (BEDANI et al., 2007). Por isso, o tratamento térmico durante o processamento da soja é necessário para inativar a enzima lipoxigenase e reduzir o sabor desagradável. Além do desenvolvimento de processos que possibilitam inativar as lipoxigenases, outras opções referentes ao sabor da soja têm sido estudadas, como obtenção, por meio de programas de melhoramento genético, de cultivares mais adaptadas para o consumo humano (MAIA; ROSSI; CARVALHO, 2006).

Nas regiões onde a população tem baixo poder aquisitivo, o consumo de soja representa uma ótima alternativa para resolver os problemas de alimentação, considerando sua riqueza em proteínas de baixo custo. Diversos produtos provenientes da soja têm sido comercializados no país e no exterior, ajudando, em parte, a tratar o déficit nutricional que aflige parte da população mundial. Nesse contexto, o extrato de soja (ES) desempenha importante papel, visto que com $1 \mathrm{~kg}$ de soja podem ser preparados aproximadamente seis litros de extrato de soja (VIEIRA et al. 1994).

Dentre os produtos derivados da soja disponíveis no Brasil, destaca-se o extrato de soja, sendo mais comumente encontrado no comércio na forma de pó ou de líquido combinado com sucos de frutas. Além desses produtos, também se encontram à venda alimentos com soja como iogurte com frutas e flan de soja. No entanto, ainda não há disponível nenhum alimento à base de soja que se assemelhe ao queijo tipo petit-suisse, que no Brasil é consumido como sobremesa, e cujas vendas são direcionadas principalmente ao público infantil.

O petit-suisse é um queijo francês que possui uma consistência de creme de queijo macia e tem um sabor doce e suave (PRUDENCIO et al., 2008). De acordo com a Instrução Normativa n ${ }^{\circ} 53$, de 29 de dezembro de 2000, o queijo tipo petit-suisse é um queijo fresco, não maturado, obtido por coagulação do leite com coalho e/ou enzimas e/ou bactérias específicas, adicionado ou não de outras substâncias alimentícias, como polpas de fruta (BRASIL, 2000). Segundo Boatto et al. (2010), a substituição do leite de vaca pelo extrato de soja eleva nutricionalmente a quantidade e a qualidade de proteínas.

Devido à baixa produção científica relacionada ao queijo tipo petit-suisse, e por não existir uma versão desse alimento à base de soja disponível no comércio brasileiro, este trabalho desenvolveu formulações e caracterizou o queijo petit-suisse com extrato de soja, aumentando, dessa forma, a disponibilidade de novos produtos industrializados que aumentem o consumo desse grão tão importante à saúde humana.

\section{SOJA}

O cultivo da soja no Brasil se iniciou em 1908, pelos japoneses, no estado de São Paulo. A partir de 1960, a produção de soja foi ampliada no Brasil através 
do crescimento econômico acelerado pelo qual o país passava na época. Em consequência, o governo brasileiro adotou políticas para facilitar o desenvolvimento e ampliação do mercado mundial de soja e derivados. Na década de 1970, a agricultura passou por transformações no modo de plantar e lidar com a lavoura através da modernização e, dentre as modificações, está a mecanização. Dessa forma, o Brasil alcançou o $2^{\circ}$ lugar como maior produtor mundial de soja, ficando atrás somente dos Estados Unidos (ROSSI; ROSSI, 2010).

A produção estimada para a safra 2015/2016 é de 102,11 milhões de toneladas, tendo um aumento de $6,1 \%$ sobre a safra $2014 / 2015$, que foi de 96,23 milhões de toneladas. A safra atual ocupou 33,23 milhões de hectares, com produtividade média de $3 \mathrm{~kg} / \mathrm{h}$. O estado com a maior produção do país foi Mato Grosso, seguido do Paraná e Rio Grande do Sul, que juntos totalizaram 60\% da soja produzida (CONAB, 2016).

A soja pertence à classe das dicotiledôneas, família leguminosa, e subfamília Papilionoides, sendo que a espécie cultivada é a Glycine Max L. Merril. Uma aplicação da soja muito conhecida é a extração do óleo vegetal e de seu subproduto, o farelo de soja. Entretanto, a população oriental conhece há anos o grão de soja e sua utilidade, criando, assim, novas formas de utilização. Os grãos inteiros da soja podem ser assados ou tostados ou ingeridos, como o broto de soja; além disso, são utilizados para a produção de extrato de soja, sobremesas de soja, iogurte de soja, sorvete de soja, tofu, tempeh, missô e molho de soja (shoyu) (MISSÃO, 2006).

A soja possui em sua composição aproximadamente $40 \%$ de proteínas, $20 \%$ de lipídios, $30 \%$ de carboidratos, $5 \%$ de fibras e $5 \%$ de cinzas (ROSSI; ROSSI, 2010). Um dos compostos biologicamente ativos são as isoflavonas, que conferem a atividade antioxidante da soja, e a caracterizam como um alimento funcional, ou seja, um alimento que pode reduzir ou prevenir doenças crônicas não transmissíveis (BAVIA et al., 2012). Para que os alimentos funcionais sejam eficientes, é necessário que o consumo seja regular e, do mesmo modo, ocorram concomitante ao aumento da ingestão de hortaliças, frutas, cereais, carne, extrato de soja e alimentos ricos em ômega-3 (VIDAL et al., 2012).

A análise química do grão de soja mostra essa cultura como uma excelente fonte de proteínas e calorias, sendo classificada como um dos cinco principais alimentos fornecedores de proteínas (carne, leite, ovos, queijo e soja). Por fonte de proteínas entende-se a quantidade adequada dos aminoácidos essenciais que devem estar presentes numa dieta para que ocorra formação e crescimento de tecidos (CARRÃO-PANIZZI, 1988).

A indústria de alimentos busca oferecer produtos novos e inovadores com o objetivo de suprir as necessidades dos consumidores. A crescente demanda por produtos mais saudáveis tem estimulado o setor de alimentos e bebidas. A 
soja se destaca dentre os alimentos cujas alegações de saúde têm sido extensivamente divulgadas pelos meios de comunicação (MOREIRA et al., 2010). A quantidade de produtos derivados da soja tem aumentado com o desenvolvimento de novos produtos que, em sua maioria, são ignorados pelos brasileiros, mas estão sendo introduzidos em seus hábitos alimentares gradativamente (ROSSI; ROSSI, 2010).

Apesar do elevado valor nutricional da soja e seus derivados, estes alimentos não possuem muita aceitabilidade devido aos sabores desagradáveis que são originados pela ação da enzima lipoxigenase sobre os ácidos graxos, formando hidroperóxidos que, ao se degradarem, formam grupos voláteis e não voláteis causadores desses sabores desagradáveis. Diversos tratamentos para remoção ou inativação das lipoxigenases da soja foram desenvolvidos na tentativa de aumentar a sua utilização como alimento humano nos países ocidentais. Porém, esses tratamentos têm alto custo, não são integralmente satisfatórios, pois insolubilizam as proteínas, e, em alguns casos, há a formação de compostos com sabor de “cozido" ou "torrado" (BORDINGNON; MANDARINO, 1994).

\subsection{Extrato de soja}

Vários produtos podem ser elaborados a partir da soja, tanto para uso direto na alimentação humana, quanto indiretamente, com a finalidade de aumentar o valor nutricional e a qualidade funcional de outros produtos. Dentre os derivados desse grão, destaca-se o extrato de soja, produto pronto para consumo, de alto valor nutritivo, de custo relativamente baixo e de fácil obtenção (FELBERG; ANTONIASSI; DELIZA, 2005). A legislação brasileira define o extrato de soja como "produto obtido a partir da emulsão aquosa resultante da hidratação dos grãos de soja, convenientemente limpos, seguido de processamento tecnológico adequado, adicionado ou não de ingredientes opcionais permitidos, podendo ser submetido à desidratação, total ou parcial” (BRASIL, 1978).

$\mathrm{O}$ extrato de soja exibe semelhanças com o leite de vaca, na aparência e composição de proteínas. Este derivado da soja não contém colesterol e é indicado às pessoas que são intolerantes à lactose ou alérgicas ao leite de vaca (ROSSI; ROSSI, 2010). De acordo com Carrão-Panizzi e Mandarino (1998), cada $100 \mathrm{ml}$ de extrato de soja contém, aproximadamente, 52 calorias; 2,5 g de carboidratos; 3,4 g de proteínas; 2,3 g de lipídios; $40 \mathrm{mg}$ de cálcio; $105 \mathrm{mg}$ de potássio; 1,2 mg de ferro; $40 \mu \mathrm{g}$ de vitamina B1 e $120 \mu \mathrm{g}$ de vitamina B2.

Na Resolução RDC no 91, de 18 de outubro de 2000, é proibida a utilização do termo "leite de soja". Aplica-se esse termo ao extrato de soja devido à aparência leitosa, semelhante à do leite de vaca. Porém o sabor, o aroma e a viscosidade entre o leite da vaca e o extrato de soja são bem distintos (BRASIL, 2000). 
Apesar do grande potencial do extrato de soja, a aceitação ainda é baixa no Brasil, devido ao sabor e ao aroma desagradáveis ao paladar dos consumidores brasileiros. Entretanto, recentemente a indústria nacional tem utilizado novas tecnologias na obtenção do extrato de soja com melhor qualidade sensorial para o mercado brasileiro. Novos produtos comerciais à base de extrato de soja em combinação com sucos ou polpa de frutas têm obtido êxito no mercado por mascarar o sabor residual da soja, indicando que os consumidores podem estar mudando sua atitude para com os produtos à base de soja (BEHRENS; SILVA, 2004).

O segmento de mercado de alimentos como soja e seus derivados tem mostrado uma ampliação considerável em virtude das diversas evidências científicas sobre os efeitos benéficos de seu consumo para a saúde, como a prevenção de doenças cardiovasculares, câncer, osteoporose e os sintomas adversos da pós-menopausa, entre outros. Com o início do crescimento da produção de soja e do conhecimento deste produto pela população, o consumo aumentou e, além do óleo de soja, principal produto comercializado, foram desenvolvidos outros produtos, como extrato de soja, extrato de soja saborizado, tofu (queijo de soja), farelo de soja, farinha de soja, concentrados e isolados proteicos de soja, proteína texturizada de soja (PTS), missô (pasta de soja) e shoyu (molho de soja), dentre outros (GUERREIRO, 2006).

\subsection{Petit-suisse}

O Dicionário Houaiss da Língua Portuguesa define a origem da palavra petit-suisse como petit-suisse (1872), de petit, "pequeno", e suisse, "suíço", nome derivado da nacionalidade de um empregado de um laticínio de Auvilliers, Normadia (França), que inventou a sua fórmula em meados do século XIX (HOUAISS; VILLAR; FRANCO, 2001).

No Brasil, este queijo é fabricado industrialmente por centrifugação da coalhada, para a separação do soro, obtendo-se o queijo "quark", que é aplicado como base para o queijo petit-suisse. Pode-se adicionar ao queijo "quark" polpa de fruta, açúcar e gordura. O queijo tipo petit-suisse é consumido como sobremesa e é dirigido ao público infantil (VEIGA et al., 2000).

As possibilidades de aumento do potencial de mercado desse produto, com a sua transformação em um alimento funcional, são amplamente favoráveis, principalmente levando-se em conta a viabilidade deste produto atingir também o público adulto (RIBEIRO et al., 2012). Dados sobre queijos tipo petit-suisse não são facilmente encontrados e o desenvolvimento de produtos funcionais lácteos ou não lácteos podem ser uma boa opção para uma alimentação saudável (CARDARELLI et al., 2008). 


\subsection{Polpa de fruta}

O aumento do consumo de frutas tropicais se dá devido ao seu valor nutritivo e efeitos terapêuticos. A utilização das polpas de frutas congeladas está em expansão nas indústrias de produtos lácteos, de sorvetes, doces etc., o que aumenta o interesse dos produtores, para o desenvolvimento de novos produtos, e dos consumidores (KUSKOSKI et al., 2006). Segundo a Instrução Normativa de $n^{\circ}$ 1, de 07 de janeiro de 2000, a polpa de fruta é o "produto não fermentado, não concentrado, não diluído, obtido pelo esmagamento de frutos polposos, através de um processo tecnológico adequado, com um teor mínimo de sólidos totais provenientes da parte comestível do fruto, específico para cada um dos mesmos" (BRASIL, 2000).

$\mathrm{Na}$ fase de colheita, há o aproveitamento integral das frutas para produção de polpas de frutas congeladas, o que evita problemas relacionados à sazonalidade. O consumo deste produto é impulsionado pela disponibilidade no comércio, praticidade em elaborar sucos in natura e pelo seu valor nutritivo (OLIVEIRA et al., 2014). A polpa de fruta congelada conserva as características químicas e sensoriais da fruta in natura, minimiza as perdas para o produtor e facilita a comercialização (SILVA et al., 2011).

\subsection{Desenvolvimento de novos produtos}

A utilização de produtos ou subprodutos de origem vegetal que contenham elevados teores de proteínas para o desenvolvimento de novos produtos tem sido destaque em diversas pesquisas. Nesses novos produtos, os nutrientes são quantificados através de análises físico-químicas, e estas avaliações são importantes para identificar o comportamento físico do produto ao longo do seu processamento e armazenamento. Além de melhorar a aparência e a qualidade nutricional dos produtos, as indústrias estão preocupadas em reduzir seus custos de produção com o desenvolvimento de novos produtos (ACUÑA; GONZÁLEZ; TORRES, 2012).

Apesar de a soja apresentar sabor desagradável ao paladar dos consumidores e isso ser um fator limitante para o seu consumo, são realizadas pesquisas com esse grão e novos produtos são desenvolvidos com soja ou seu extrato, além do subproduto, okara, que é considerado um resíduo gerado a partir do processamento da soja. O consumo desse produto de origem vegetal é baixo devido ao seu sabor e aos hábitos alimentares. A tendência de consumir alimentos mais saudáveis favorece o consumo da soja devido aos seus valores nutricionais, mas a maioria das pessoas que não consomem esses grãos não possui informações íntegras sobre a composição da soja e não adquirem o hábito de consumir esses produtos em longo prazo, e produtos benéficos ao organismo têm ação somente com o consumo por um período longo (BEDANI et al., 2007). 


\subsection{Gomas alimentícias}

A mistura de gomas alimentícias é comum nas indústrias. A combinação de gomas influencia no processamento de alimentos devido às características que cada goma alimentar possui. Algumas gomas são utilizadas como espessantes e para retenção de água, promovendo efeitos na aparência, estabilidade ou reologia dos produtos. A quantidade adicionada de gomas alimentícias nos produtos é pequena, e por isso, apesar de algumas gomas possuírem elevado valor de custo, sua utilização não é relevante no preço final do produto (INSUMOS, 2014). De acordo com Cui (2005), as gomas de polissacarídeos têm sido utilizadas em produtos de padaria e lácteos para melhorar a textura e as características sensoriais dos produtos, e como agentes de gelificação para desenvolver sobremesas.

Dentre algumas gomas alimentícias, destacam-se pectina, goma guar e xantana. As pectinas são elementos predominantes das paredes celulares de plantas e são encontradas em frutas e vegetais. Pectinas comerciais são desenvolvidas a partir de alguns produtos da indústria alimentícia, como a polpa da maçã e cascas (albedo) de frutas cítricas. As pectinas são uma classe de polissacarídeos ligados a polímeros galacturona e ramnogalacturona (CUI, 2005), são agentes de gelificação e têm comportamento próximo do newtoniano (INSUMOS, 2014).

Segundo Schorsch, Garnie e Doublier (1995), a xantana é um polissacarídeo originado por fermentação com a bactéria Xanthomonas campestris. Esse polissacarídeo é aplicado em alimentos, medicamentos e cosméticos por causa de suas propriedades funcionais, físicas e químicas (XUEWU et al., 1996). A goma xantana é uma solução viscosa que é moderadamente afetada pela temperatura ou pelo $\mathrm{pH}$, mas não gelifica a solução, e possui comportamento pseudoplástico, propriedade relevante para liberação do sabor e sensibilidade bucal. A goma xantana age como espessante, estabilizante e, em combinação com outras gomas, apresenta textura lisa e cremosa a alimentos líquidos. Esta goma é solúvel em água quente ou fria, mesmo em baixas concentrações apresenta alta viscosidade e apresenta sinergismo com a goma guar. As aplicações da goma xantana englobam queijos, patês, molhos, produtos cárneos, sorvetes, sobremesas, sopas e geleias (previne sinérese) (INSUMOS, 2014).

A goma xantana é, da mesma maneira que muitas gomas (exceto o amido), não digerível pelo organismo humano, auxilia na diminuição do conteúdo calórico de alimentos e em sua passagem pelo interior do trato gastrointestinal. $\mathrm{O}$ valor calórico da goma xantana é de aproximadamente $0,6 \mathrm{kcal} / \mathrm{g}$ (FIB, 2010).

A goma guar é originada a partir de sementes de Cyamopsis tetragonolobus, sendo aplicada como espessante e estabilizante para sorvetes e lácteos. As paredes 
das células de sementes são ricas em manana e galactomanana. Os galactomanana mais conhecidos são gomas de alfarroba e guar. A taxa de solubilidade e hidratação dessas gomas podem ser influenciadas pelo tamanho da partícula, do $\mathrm{pH}$, temperatura e métodos de agitação. Há um aumento sinérgico na viscosidade ou resistência do gel por mistura de gomas galactomanana com certos polissacarídeos, como xantana, $\kappa$-carragena e agarose (CUI, 2005). A viscosidade das soluções com a goma guar aumenta com o aumento da concentração da goma em água fria, sendo que pode haver influência com a temperatura, $\mathrm{pH}$, tempo, grau de agitação, tamanho da partícula da goma alimentícia e presença de outros sólidos. A goma guar dispersa-se em água fria ou quente, possui alta viscosidade em baixas concentrações, não gelifica, forma soluções viscosas quando hidratada em água fria e suas soluções apresentam propriedades pseudoplásticas, não tixotrópicas. É instável em pH muito baixo e sob condições normais exibe características gelo-degelo (INSUMOS, 2014).

\section{MATERIAIS E MÉTODOS}

Os grãos de soja cultivar BRS 232, safra 2010/2011, foram fornecidos pela Embrapa Soja, localizada em Londrina, Paraná. Os queijos petit-suisse foram preparados a partir da homogeneização do coagulado obtido, polpa de fruta congelada (Polpa Norte) sabores maracujá e morango, açúcar (Cristal), corante artificial (Mix Coralim), aromatizante artificial (Mix SaborFort) e mix goma guar e xantana (Leve Crock), com a utilização de mixer doméstico (Taurus Happy), para a realização dos testes prévios, e liquidificador industrial (Metvisa LQ 15) para a elaboração dos produtos finais; após a adaptação das formulações, o tempo de agitação foi realizado até a homogeneização completa.

\subsection{Obtenção do extrato de soja}

A obtenção do extrato de soja foi baseada em Benassi, Yamashita e Prudêncio (2011), com algumas modificações na proporção soja:água (1:10). O extrato foi obtido a partir das seguintes etapas: os grãos de soja foram imersos em água em ebulição por cinco minutos (branqueamento) e, em seguida, resfriados em água com gelo para inativação das enzimas lipoxigenases; então, foram dispostos na proporção 1:3 de água em temperatura ambiente por dezesseis horas (maceração), etapa que auxilia no clareamento do extrato de soja. Posteriormente, os grãos macerados foram drenados e triturados por cinco minutos em liquidificador industrial com água a $90{ }^{\circ} \mathrm{C}$, na proporção $1: 10$ do volume da soja seca, descontando o que foi absorvido na maceração. Logo depois foram separados, por centrifugação, o extrato de soja do subproduto sólido, okara (Figura 3.1). 


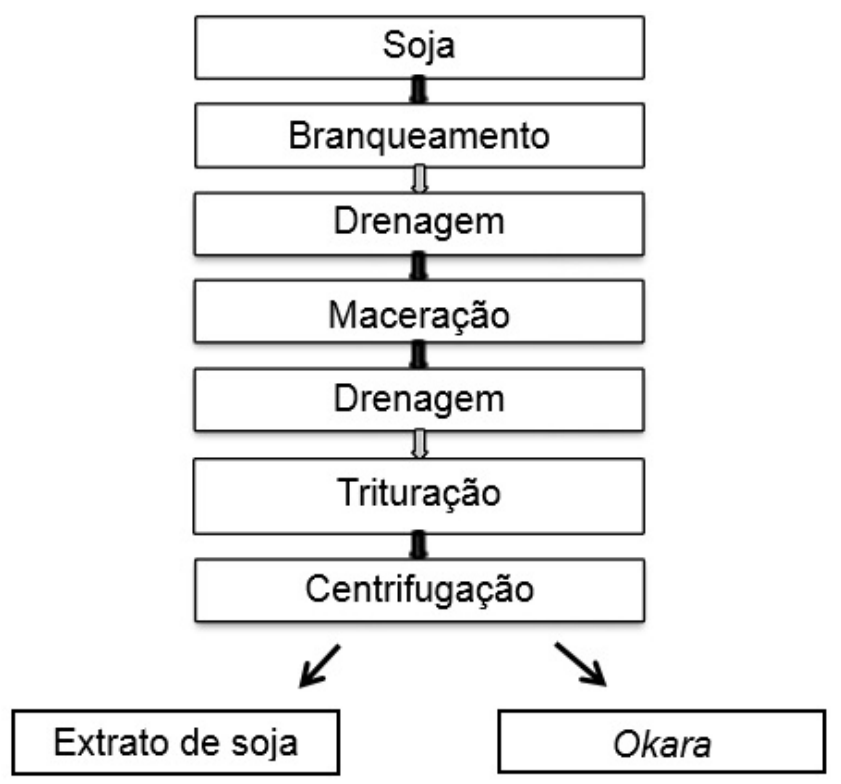

Figura 3.1 Diagrama de obtenção do Extrato de Soja (ES)

\subsection{Processamento do queijo petit-suisse com extrato de soja}

O extrato de soja foi levado à fervura, em recipiente de inox tampado, sobre o fogo direto por dez minutos; posteriormente foi retirado do fogo para a temperatura atingir $75-76{ }^{\circ} \mathrm{C}$ (temperatura de coagulação), mantido por dez minutos em banho-maria, onde adicionou-se $0,15 \%$ de ácido láctico em relação ao volume do extrato de soja, e homogeneizado. A coagulação foi realizada por vinte minutos a $75-76^{\circ} \mathrm{C}$. Após a coagulação, realizou-se o corte do coágulo com auxílio de uma espátula, e transferiu-se o coágulo para uma forma plástica perfurada com dessorador. Em seguida, aplicou-se um peso de 300 gramas sobre a superfície do coágulo por dez minutos, sem pressioná-lo. Na sequência, o produto no dessorador foi acondicionado em recipiente apropriado, de forma que o mantivesse em suspensão sob refrigeração por dezessete horas para eliminação do soro. Este método de refrigeração por dezessete horas foi baseado em Matias (2011) e, após esse processo, o coagulado foi pesado e homogeneizado com os outros ingredientes (Figura 3.2).

A partir de testes prévios para obtenção do produto final do queijo petit-suisse com extrato de soja, padronizou-se a formulação para ambos os sabores (Tabela 3.1). O corante artificial foi calculado de acordo com as recomendações do fabricante e o aroma artificial foi adicionado por tentativas, para avaliar a porcentagem mais adequada a ser acrescida. 


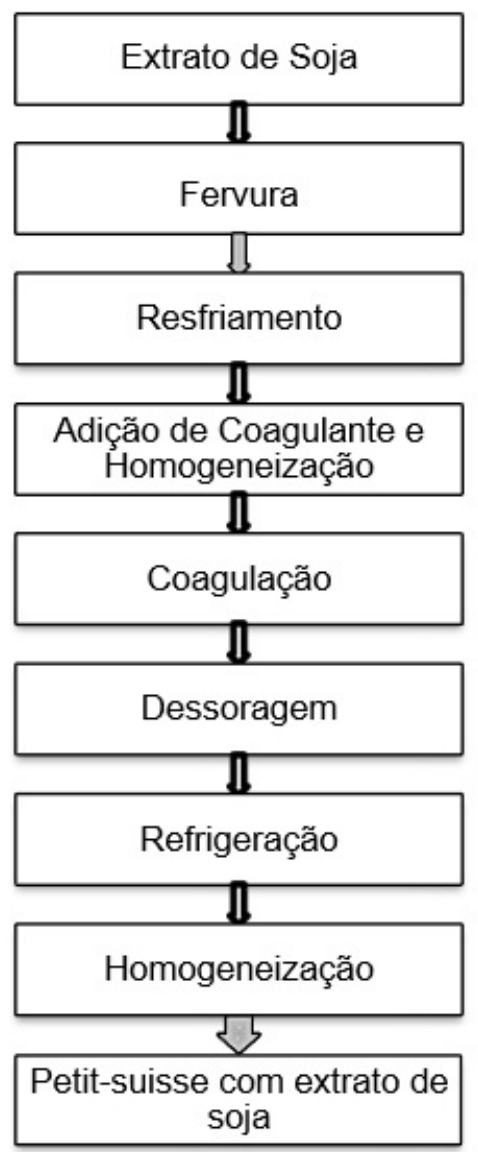

Figura 3.2 Diagrama de obtenção dos queijos petit-suisse com extrato de soja

Tabela 3.1 ormulação padrão para os queijos petit-suisse com extrato de soja, sabor morango e maracujá $(\mathrm{g} / 100 \mathrm{~g})$

\begin{tabular}{cc}
\hline Ingredientes & Formulações $(\mathrm{g} / 100 \mathrm{~g})$ \\
\hline Coágulo & 66,33 \\
Polpa de fruta & 20,00 \\
Açúcar Cristal & 13,33 \\
Corante Artificial & 0,08 \\
Aroma Artificial & 0,06 \\
Goma guar e xantana & 0,2 \\
\hline
\end{tabular}

\subsection{Composição proximal}

Houve a determinação de umidade em estufa a $105^{\circ} \mathrm{C}$ com circulação de ar, das cinzas por carbonização seguida de incineração em mufla a $550^{\circ} \mathrm{C}$, das pro- 
teínas pelo método Micro Kjeldahl e cálculo do teor utilizando fator de correção 6,25, dos lipídios quantificados por extração em Soxhlet com éter de petróleo, segundo os métodos descritos na A.O.A.C. (1995). Os carboidratos foram calculados por diferença [100-(umidade+cinzas+lipídios+proteínas)].

\subsection{Análises físico-químicas}

Nas formulações de petit-suisse foram realizadas as análises de $\mathrm{pH}$, utilizando potenciômetro com eletrodo vidro (MS TECNOPON - modelo PA210), e acidez total titulável (ATT) determinada por titulação com solução padronizada de hidróxido de sódio 0,1 M, segundo o Instituto Adolfo Lutz (2008).

\subsection{Análise sensorial}

Foi realizado teste afetivo de aceitação e teste de intenção de compra. Os testes de aceitação foram aplicados em dois dias, em cabines individuais, com 50 julgadores não treinados de ambos os gêneros para cada dia de análise, sendo avaliados os atributos cor, aroma, sabor, textura e aceitação global a partir de uma escala hedônica híbrida de zero a dez pontos, onde o ZERO corresponde a "desgostei extremamente" e DEZ "gostei extremamente", segundo proposta de Villanueva, Petenate e Silva (2005). A intenção de compra foi avaliada com uma escala hedônica de cinco pontos, em que cinco representa "certamente compraria" e um "certamente não compraria".

Essa análise teve aprovação pelo Comitê de Bioética e Ética em Pesquisa da Irmandade da Santa Casa de Londrina (BIOISCAL), por meio do projeto $\mathrm{n}^{\circ}$ 355/10 - CAAE: 0015.0.083.000 - 10.

\subsection{Tratamento estatístico}

Os dados das análises foram avaliados pelo software Statistica 10.0, utilizando análise de variância (ANOVA) e comparando as médias com o teste de Tukey ao nível de $5 \%$ de significância.

\section{RESULTADOS E DISCUSSÃO}

Foram realizados testes prévios utilizando a polpa de fruta sabor morango e maracujá para obtenção do produto final do queijo petit-suisse com extrato de soja (Tabelas 2 e 3). Nos testes 1 a 6 , foi adicionada polpa de fruta sabor morango, açúcar, aroma artificial e corante artificial. Nos seguintes testes, foi adicionada, também, polpa de maracujá. Nos testes 9 e 12 foi incorporado pectina, e no teste 8 foi adicionado mix de goma guar e xantana. O produto contendo pectina apresentou sinergia diferente do queijo com mix de goma guar e xantana, pois essas gomas alimentares possuem características distintas. 
Tabela 3.2 Formulações dos testes prévios realizados para desenvolver os queijos petit-suisse com extrato de soja

\begin{tabular}{ccccccccc}
\hline $\begin{array}{c}\text { Tes- } \\
\text { tes }\end{array}$ & $\begin{array}{c}\text { Coá- } \\
\text { gulo }\end{array}$ & $\begin{array}{c}\text { Polpa de } \\
\text { Morango }\end{array}$ & $\begin{array}{c}\text { Polpa de } \\
\text { Maracujá }\end{array}$ & $\begin{array}{c}\text { Aḉćcar } \\
\text { Cristal* }^{*}\end{array}$ & $\begin{array}{c}\text { Corante } \\
\text { Artificial* }\end{array}$ & $\begin{array}{c}\text { Aroma } \\
\text { Artificial* }^{*}\end{array}$ & $\begin{array}{c}\text { Pectina } \\
\text { Cítrica* }^{*}\end{array}$ & $\begin{array}{c}\text { Goma guar e } \\
\text { xantana* }^{*}\end{array}$ \\
\hline 1 & $\checkmark$ & $\checkmark$ & & $\checkmark$ & $\checkmark$ & $\checkmark$ & - & - \\
2 & $\checkmark$ & $\checkmark$ & & $\checkmark$ & $\checkmark$ & $\checkmark$ & - & - \\
3 & $\checkmark$ & $\checkmark$ & & $\checkmark$ & $\checkmark$ & $\checkmark$ & - & - \\
4 & $\checkmark$ & $\checkmark$ & & $\checkmark$ & $\checkmark$ & $\checkmark$ & - & - \\
5 & $\checkmark$ & $\checkmark$ & & $\checkmark$ & $\checkmark$ & $\checkmark$ & - & - \\
6 & $\checkmark$ & $\checkmark$ & & $\checkmark$ & $\checkmark$ & $\checkmark$ & - & - \\
7 & $\checkmark$ & $\checkmark$ & $\checkmark$ & $\checkmark$ & $\checkmark$ & $\checkmark$ & - & - \\
8 & $\checkmark$ & $\checkmark$ & $\checkmark$ & $\checkmark$ & $\checkmark$ & $\checkmark$ & - & - \\
9 & $\checkmark$ & $\checkmark$ & $\checkmark$ & $\checkmark$ & $\checkmark$ & $\checkmark$ & $\checkmark$ & - \\
10 & $\checkmark$ & $\checkmark$ & $\checkmark$ & $\checkmark$ & $\checkmark$ & $\checkmark$ & $\checkmark$ & - \\
11 & $\checkmark$ & $\checkmark$ & $\checkmark$ & $\checkmark$ & $\checkmark$ & $\checkmark$ & $\checkmark$ & - \\
12 & $\checkmark$ & $\checkmark$ & $\checkmark$ & $\checkmark$ & $\checkmark$ & $\checkmark$ & $\checkmark$ & - \\
13 & $\checkmark$ & $\checkmark$ & $\checkmark$ & $\checkmark$ & $\checkmark$ & $\checkmark$ & - & $\checkmark$ \\
14 & $\checkmark$ & $\checkmark$ & $\checkmark$ & $\checkmark$ & $\checkmark$ & $\checkmark$ & - & $\checkmark$ \\
\hline
\end{tabular}

*Calculado em relação ao coágulo.

Tabela 3.3 Formulação dos testes realizados $(\mathrm{g} / 100 \mathrm{~g})$

\begin{tabular}{cccccccc}
\hline Testes & Coágulo & $\begin{array}{c}\text { Polpa de } \\
\text { fruta* }^{*}\end{array}$ & $\begin{array}{c}\text { Açúcar } \\
\text { Cristal* }\end{array}$ & $\begin{array}{c}\text { Corante } \\
\text { Artificial* }\end{array}$ & $\begin{array}{c}\text { Aroma } \\
\text { Artificial* }\end{array}$ & $\begin{array}{c}\text { Pectina } \\
\text { Cítrica* }^{*}\end{array}$ & $\begin{array}{c}\text { Goma guar e } \\
\text { xantana* }^{*}\end{array}$ \\
\hline 1 & 59,76 & 20 & 20 & 0,08 & 0,16 & - & - \\
3 & 39,92 & 30 & 30 & 0,08 & - & - & - \\
4 & 29,92 & 40 & 30 & 0,08 & - & - & - \\
5 & 49,86 & 30 & 20 & 0,08 & 0,06 & - & - \\
6 & 66,53 & 20 & 13,33 & 0,08 & 0,06 & - & - \\
7 & 66,53 & 20 & 13,33 & 0,08 & 0,06 & - & - \\
8 & 66,53 & 20 & 13,33 & 0,08 & 0,06 & - & - \\
9 & 66,43 & 20 & 13,33 & 0,08 & 0,06 & 0,1 & - \\
10 & 66,33 & 20 & 13,33 & 0,08 & 0,06 & 0,2 & - \\
11 & 66,33 & 20 & 13,33 & 0,08 & 0,06 & 0,2 & - \\
12 & 66,33 & 20 & 13,33 & 0,08 & 0,06 & 0,2 & - \\
13 & 66,33 & 20 & 13,33 & 0,08 & 0,06 & - & 0,2 \\
14 & 66,33 & 20 & 13,33 & 0,08 & 0,06 & - & 0,2 \\
\hline
\end{tabular}

*Calculado em relação ao coágulo. 
No teste 1, a formulação apresentou grânulos após a homogeneização e sabor intenso de soja. Para minimizar o sabor da soja, nos testes 2 e 3 foram adicionados $10 \%$ e $20 \%$ a mais de polpa de fruta, respectivamente, e $10 \%$ a mais de açúcar; no entanto, como resultado, o gosto ficou muito doce e a formulação que conteve $40 \%$ de polpa apresentou sabor forte de morango. Sendo assim, diminuiu-se a quantidade de açúcar (para 20\%) e de polpa de fruta (para 30\%) (teste 4). E no teste 5 diminuiu-se ainda mais o açúcar (para 13,33\%) e a polpa de fruta (para 20\%). Devido à impossibilidade de homogeneização completa do petit-suisse com extrato de soja, houve a formação de grânulos em todos os testes, não sendo eficiente a utilização do liquidificador doméstico. Os demais testes foram realizados utilizando um mixer doméstico para homogeneização dos ingredientes, o que resultou num produto mais homogêneo e sem grânulos.

O teste 7 apresentou um produto homogêneo, portanto, foi estocado sob refrigeração, para avaliar a formação ou não de soro, o que aconteceu após três dias de armazenamento. Por isso, nos testes 9 a 12, foi adicionada pectina cítrica nas proporções de $0,1 \%$ e $0,2 \%$; no entanto, essa adição não interferiu nas características do teste anterior, ou seja, na diminuição do soro aparente.

A partir daí, nos testes seguintes foi adicionado um peso de 300 gramas por dez minutos sobre o coágulo obtido, sem pressão manual, para acelerar o processo de dessoramento. Em seguida, homogeneizaram-se os ingredientes para a elaboração do petit-suisse com extrato de soja, os quais foram submetidos à refrigeração. Porém este processo também não foi suficiente para reduzir a formação de soro após três dias.

Para evitar a formação de soro, Matias (2011) relatou o uso de dessoragem do coagulado em refrigeração por dezessete horas. Novos testes $(12,13$ e 14) foram realizados aplicando essa técnica durante a dessoragem do coágulo e, após homogeneizarem-se os ingredientes, acondicionou-se o produto em refrigeração para avaliar a formação de soro, que foi menor em relação aos outros testes, mas ainda existiu. Então, testou-se o uso de pectina ou mix de goma guar e xantana para inibir a dessoragem. Após refrigeração, houve baixa formação de soro até seis dias em refrigeração quando utilizada a pectina; no entanto, com a utilização da goma guar e xantana não houve formação de soro durante a refrigeração.

As características de textura, cor, sabor e dessoragem dos petit-suisse com extrato de soja foram observadas durante os testes (Tabela 3.4). Nos testes 1 a 6 , como houve a formação de grânulos devido à homogeneização inadequada com o liquidificador doméstico, a dessoragem dos produtos não pôde ser avaliada. Nos testes 7 a 14, com a utilização do mixer doméstico, foi possível avaliar a dessoragem. Nos testes 9 a 12 foi adicionada pectina, que não influenciou nas características finais dos produtos, apresentando textura menos consistente, assim como dos testes anteriores. 
Nos testes 11 e 12 foram realizados os processos de dessoragem com a utilização de um peso de 300 gramas por dez minutos, sem pressão manual, mas este procedimento não foi eficiente na dessoragem. No teste 12 , além do peso, o petit-suisse foi submetido à dessoragem por dezessete horas sob refrigeração em suspensão, o que resultou num produto consistente devido à eliminação de soro durante essa suspensão.

Nos testes 13 e 14, foi adicionado mix de goma guar e xantana para verificar a interação destes componentes com os queijos. Após os processos de refrigeração, foi verificado que não houve formação de soro aparente nos produtos, portanto as gomas foram eficientes no processo de retenção do soro. Segundo FIB (2010), dentre as propriedades da solução de goma xantana, destaca-se sua interação com a goma guar. A adição de goma guar numa solução de goma xantana em temperatura de refrigeração causa sinergismo, aumentando a viscosidade.

Tabela 3.4 Características dos queijos petit-suisse com extrato de soja

\begin{tabular}{ccccc}
\hline Testes & Textura & Cor & Sabor & Dessoragem \\
\hline 1 & Grânulos & Característica & Forte & Não avaliada \\
2 & Grânulos & Característica & Forte & Não avaliada \\
3 & Grânulos & Característica & Forte & Não avaliada \\
4 & Grânulos & Característica & Médio & Não avaliada \\
5 & Grânulos & Característica & Médio & Não avaliada \\
6 & Grânulos & Característica & Médio & Não avaliada \\
7 & Homogêneo e rígido & Característica & Médio & Houve formação \\
8 & Homogênea & Característica & Médio & Houve formação \\
9 & Menos consistente & Característica & Médio & Houve formação \\
10 & Menos consistente & Característica & Médio & Houve formação \\
11 & Menos consistente & Característica & Médio & Houve formação \\
12 & Consistente & Característica & Baixo & Baixa formação \\
13 & Firme & Característica & Médio & Baixa formação \\
14 & Firme e cremosa & Característica & Baixo & Não houve formação \\
\hline
\end{tabular}

Uma nova produção foi elaborada a partir da formulação com as condições que apresentaram os melhores resultados nos testes prévios: $66,33 \%$ de coágulo, $20 \%$ de polpa de fruta, $13,33 \%$ de açúcar, $0,08 \%$ de corante artificial, $0,06 \%$ de aroma artificial e $0,2 \%$ de goma guar e xantana. Esses produtos foram avaliados pelas características químicas, físico-químicas e sensoriais.

A Tabela 3.5 apresenta os valores referentes às análises de composição proximal dos petit-suisse sabor maracujá e morango. Verificou-se que as amostras 
diferiram entre si estatisticamente nas determinações de umidade e proteínas, e se igualaram nos teores de lipídios e cinzas. Apesar dos produtos conterem os mesmos ingredientes, o teor de proteínas foi diferente, possivelmente devido à elaboração destes produtos em momentos diferentes.

Tabela 3.5 Composição proximal dos queijos petit-suisse com extrato de soja, sabor maracujá e morango $(\mathrm{g} / 100 \mathrm{~g}$ )

\begin{tabular}{|c|c|c|c|c|c|}
\hline Formulações & Umidade & Lipídios & Proteínas & Cinzas & Carboidratos \\
\hline $\begin{array}{l}\text { Queijo petit- } \\
\text { suisse com } \\
\text { extrato de } \\
\text { soja sabor } \\
\text { maracujá }\end{array}$ & $67,59 \pm 0,21^{b}$ & $7,27 \pm 0,11^{a}$ & $11,58 \pm 0,30^{a}$ & $0,40 \pm 0,01^{a}$ & 13,16 \\
\hline $\begin{array}{l}\text { Queijo petit- } \\
\text { suisse com } \\
\text { extrato de } \\
\text { soja sabor } \\
\text { morango }\end{array}$ & $68,71 \pm 0,02^{a}$ & $7,01 \pm 0,33^{a}$ & $9,48 \pm 0,29^{b}$ & $0,47 \pm 0,08^{a}$ & 14,33 \\
\hline
\end{tabular}

Média \pm Desvio padrão; os valores com letras iguais, na mesma coluna, não diferiram estatisticamente entre si, ao nível de $5 \%$ de significância; *: calculados por diferença.

Prudencio et al. (2008) desenvolveram queijo petit-suisse com e sem soro retido de queijo, e avaliaram a adição de betalaínas de beterrabas e antocianinas de uvas, com o objetivo de obter coloração semelhante para os produtos comerciais. O queijo com $30 \%$ de leite e $70 \%$ de soro retido apresentou teores de umidade $(75,53 \%)$, cinzas $(0,73 \%)$, proteínas $(6,22 \%)$ e lipídios $(4,60 \%)$ distantes das análises do presente trabalho, provavelmente devido à utilização do leite de vaca como matéria-prima, visto que este contém composição diferente do extrato de soja, porém os carboidratos $(12,90 \%)$ apresentaram valor próximo ao queijo petit-suisse com extrato de soja sabor maracujá (13,17\%). O queijo com $100 \%$ de leite desenvolvido pelos autores apresentou os seguintes valores: umidade, $76,22 \%$; cinzas, $0,72 \%$; proteínas, $6,71 \%$; lipídios, $4,30 \%$; e carboidratos, $12,08 \%$, sendo que os teores de proteínas, lipídios e carboidratos foram menores se comparados com os valores obtidos dos queijos petit-suisse com extrato de soja, pois os produtos à base de soja apresentaram maiores teores destes componentes que os queijos lácteos.

Boatto et al. (2010) desenvolveram queijo tipo petit-suisse de soja sabor morango, enriquecido com cálcio, a partir da cultivar de soja Embrapa 48 (soja comum) e BRS 213 (soja livre de lipoxigenase), apresentando valores de 67,53\% 
(Embrapa 48) e 69,43\% (BRS 213) para umidade; 0,35\% (Embrapa 48) e 0,33\% (BRS 213) para cinzas; 5,43\% (Embrapa 48) e 4,70\% (BRS 213) para proteína bruta; 4,27\% (Embrapa 48) e 2,92\% (BRS 213) para lipídios; e 22,42\% (Embrapa 48 ) e $22,62 \%$ (BRS 213) para carboidratos. Os valores de cinzas, proteínas e lipídios obtidos pelos autores apresentaram teores abaixo dos encontrados na presente pesquisa para os queijos petit-suisse com extrato de soja.

Em outra pesquisa, realizada por Maruyama et al. (2006), relativa ao queijo petit-suisse probiótico com diferentes combinações de gomas (xantana, carragena, guar e pectina) para avaliação da textura instrumental dos produtos, a formulação F1 (goma xantana, 0,1875\%; carragena, 0,1875\%; e guar, 0,375\%) apresentou umidade de $70,48 \%$, formulação que apresentou melhores resultados para os autores na estabilidade da firmeza durante o armazenamento do produto. A umidade do queijo sabor morango foi próxima $(68,71 \%)$ ao do queijo elaborado por Maruyama et al. (2006) e, além disso, a estabilidade da consistência durante o armazenamento também foi verificada nos queijos petit-suisse com extrato de soja e adição do mix goma guar e xantana.

Durante o processamento, os queijos petit-suisse com extrato de soja foram submetidos ao tratamento térmico de $75-76{ }^{\circ} \mathrm{C}$, e na análise de proteínas as amostras apresentaram valores para a formulação com maracujá (11,58\%), e morango $(9,48 \%)$. Os teores de proteínas dos queijos petit-suisse com extrato de soja sabor morango se aproximaram dos encontrados por Veiga e Viotto (2001), que analisaram o efeito do tratamento térmico do leite no teor de proteínas e de nitrogênio não-proteico de queijo petit-suisse sabor morango fabricado por ultrafiltração de leite coagulado. O petit-suisse submetido a tratamento térmico $85^{\circ} \mathrm{C} / 30$ min e 72 ${ }^{\circ} \mathrm{C} / 15$ seg obteve teor de proteínas de $8,95 \%$ e 9,02\% respectivamente. Os valores foram semelhantes ao queijo petit-suisse com extrato de soja sabor morango, provavelmente devido à utilização do mesmo sabor de polpa de fruta.

Matias (2011) desenvolveu um alimento probiótico à base de soja com polpa de fruta, sendo produzidas três formulações: F1 (controle), queijo petit-suisse probiótico de base láctea; F2, queijo de soja probiótico com creme de leite de origem láctea - base láctea parcialmente substituída por soja; e F3, queijo de soja probiótico com creme de soja - base láctea totalmente substituída por soja. As amostras apresentaram valores de $63,90 \%$ (F1), 67,25\% (F2) e 66,69\% (F3) para umidade; 2,43\% (F1), 6,74\% (F2) e 6,05\% (F3) para lipídios; 1,09\% (F1), 0,48\% (F2), 0,47\% (F3) para cinzas; $17,10 \%$ (F1), 10,75\% (F2) e 11,39\% (F3) para proteínas; e $15,48 \%$ (F1), 14,78\% (F2) e 15,40\% (F3) para carboidratos. Os teores da F2 e F3 foram semelhantes ao presente trabalho, possivelmente devido à composição da variedade BRS 257 da soja in natura utilizada pela autora ser similar à BRS 232 utilizada neste trabalho. 
Cardarelli et al. (2008) desenvolveram um queijo petit-suisse sabor morango e analisaram a influência de ingredientes prebióticos inulina, oligofrutose e oligossacarídeos de mel durante o armazenamento do produto. Foram desenvolvidos oito tratamentos que, entre T1 e T7, variavam somente no teor de inulina, oligofrutose e oligossacarídeos, e, em T8 (controle), as amostras foram analisadas em relação à composição proximal. Todos os tratamentos apresentaram teores de cinzas acima do valor dos resultados obtidos nos queijos da presente pesquisa. Os autores obtiveram baixos teores de lipídios quando comparados com os produtos queijos petit-suisse com extrato de soja. A umidade (66,81\%) do T8 (controle) foi semelhante à umidade dos queijos petit-suisse com extrato de soja, e os teores de proteínas dos tratamentos se aproximaram dos valores obtidos para o queijo petit-suisse com extrato de soja sabor morango $(9,48 \%)$.

Os resultados das análises de $\mathrm{pH}$ e acidez total titulável (ATT) diferiram entre si estatisticamente (Tabela 3.6), provavelmente devido ao processamento dos queijos, pois os produtos sabor morango e maracujá foram elaborados em momentos diferentes, e diferiram também em relação à composição das polpas de frutas.

Tabela 3.6 Análises de pH e acidez total titulável (ATT) dos queijos petit-suisse com extrato de soja, sabor maracujá e morango

Formulaçōes $\mathrm{pH}$
Acidez Total Titulável (g. de ácido cítrico/ $100 \mathrm{~g}$ )
Queijo petit-suisse com extra-
to de soja sabor maracujá
$3,84 \pm 0,01^{\mathrm{b}}$
$0,02 \pm 0,01^{a}$
Queijo petit-suisse com extra-
to de soja sabor morango
$4,73 \pm 0,01^{a}$
$0,01 \pm 0,01^{b}$

Média Desvio padrão; os valores com letras iguais, na mesma coluna, não diferiram estatisticamente entre si, ao nível de $5 \%$ de significância.

Os valores de $\mathrm{pH}$ e acidez total titulável das polpas de fruta de maracujá e morango estão apresentados na Tabela 3.7. De acordo com o Regulamento Técnico para Fixação dos Padrões de Identidade e Qualidade (BRASIL, 2000), que define os parâmetros físico-químicos para polpa de maracujá, o pH deve ser mínimo de 2,7 e máximo de 3,8, com ATT mínimo de 2,50g de ácido cítrico/100g. Este regulamento não define os parâmetros para a polpa de morango. O resultado do $\mathrm{pH}$ da polpa de maracujá está dentro dos parâmetros físico-químicos estabelecidos pelo Ministério da Agricultura, Pecuária e Abastecimento (MAPA), enquanto o resultado para acidez total titulável da polpa está abaixo desses parâmetros (1,40 g de ácido cítrico/100 g). 
Prudencio et al. (2008) obtiveram pH do queijo 1 (com $30 \%$ de leite e $70 \%$ de soro retido) e queijo 2 (com $100 \%$ de leite) de 4,55 e 4,57, respectivamente, valores acima dos queijos petit-suisse com extrato de soja sabores maracujá $(3,84)$ e abaixo do $\mathrm{pH}$ do sabor morango $(4,73)$, provavelmente devido às polpas de fruta sabores maracujá e morango utilizadas apresentarem $\mathrm{pH}$ mais ácido, de 2,73 e 3,23 , respectivamente.

Boatto et al. (2010) analisaram o pH de queijo tipo petit-suisse de soja cultivar Embrapa 48 e BRS 213, enriquecido com cálcio sabor morango, que apresentou $\mathrm{pH}$ de 4,30 (Embrapa 48) e 4,42 (BRS 213). Também avaliaram a acidez total das mesmas amostras, obtendo 6,26\% (Embrapa 48) e 6,02\% (BRS 213), valores acima dos obtidos nesta pesquisa.

Tabela 3.7 Análises de pH e acidez total titulável (ATT) das polpas de frutas $(\mathrm{g} / 100 \mathrm{~g})$

\begin{tabular}{ccc}
\hline Formulações & $\mathbf{p H}$ & $\begin{array}{c}\text { Acidez Total Titulável } \\
\text { (g. de ácido cítrico/100 g) }\end{array}$ \\
\hline Polpa de fruta sabor maracujá & $2,73 \pm 0,01^{\mathrm{b}}$ & $1,40 \pm 0,01^{\mathrm{a}}$ \\
Polpa de fruta sabor morango & $3,23 \pm 0,01^{\mathrm{a}}$ & $0,14 \pm 0,01^{\mathrm{b}}$ \\
\hline
\end{tabular}

Média \pm Desvio padrão; os valores com letras iguais, na mesma coluna, não diferiram estatisticamente entre si, ao nível de $5 \%$ de significância.

Nos testes sensoriais de aceitação, o perfil dos provadores dos queijos petit-suisse com extrato de soja sabor maracujá e morango foram semelhantes. Para a formulação sabor maracujá, $64 \%$ eram do gênero feminino e $36 \%$ do gênero masculino. Dentre as mulheres, $14 \%$ nunca consumiram queijo petit-suisse. Metade $(50 \%)$ dos provadores tinha idade entre 18 a 20 anos, $38 \%$ entre 21 a 25 anos, $6 \%$ de 26 a 30 anos e $6 \%$ dos provadores tinham idades acima de 30 anos. Entre os provadores para o queijo petit-suisse com extrato de soja sabor morango, $56 \%$ dos provadores eram do gênero feminino e $44 \%$ do gênero masculino; $16 \%$ das mulheres nunca haviam consumiram queijo petit-suisse. Havia $42 \%$ de provadores entre 18 e 20 anos, $42 \%$ de 21 a 25 anos, $6 \%$ entre 26 a 30 anos e $10 \%$ tinham idade superior a 30 anos.

Para as duas amostras de queijos petit-suisse com extrato de soja foram realizados os testes de aceitação (Tabela 3.8). O aroma e a cor das amostras diferiram estatisticamente entre si devido às polpas de frutas utilizadas - maracujá $(7,42$ para aroma e 7,26 para cor) e morango (5,39 para aroma e 8,06 para cor) -, e, na escala utilizada, as notas representaram que os provadores "não gostaram nem desgostaram" do aroma de morango do queijo e "gostaram moderadamente" e/ ou "gostaram muito" dos atributos aroma de maracujá e as cores dos produtos. 
Os valores das amostras para os atributos sabor, textura e aceitação global não apresentaram diferença estatística entre si. Com relação aos atributos aroma e sabor, o petit-suisse sabor maracujá obteve maiores notas (7,42 e 6,01), e "gostei moderadamente" e "gostei ligeiramente", respectivamente. O queijo petit-suisse com extrato de soja sabor maracujá obteve maior nota, provavelmente devido ao maracujá ter mascarado o sabor residual da soja, pois esta polpa apresentar maior acidez. A aceitação das amostras representou, na escala utilizada, que os provadores "gostaram ligeiramente" e/ou "gostaram moderadamente" dos dois queijos petit-suisse com extrato de soja.

Tabela 3.8 Análise sensorial de aceitação dos queijos petit-suisse com extrato de soja sabor maracujá e morango

\begin{tabular}{ccc}
\hline Atributos & Maracujáa & Morango \\
\hline Aroma & $7,42 \pm 2,16^{\mathrm{a}}$ & $5,39 \pm 2,66^{\mathrm{b}}$ \\
Cor & $7,26 \pm 2,32^{\mathrm{b}}$ & $8,06 \pm 1,54^{\mathrm{a}}$ \\
Sabor & $6,01 \pm 2,71^{\mathrm{a}}$ & $5,44 \pm 2,64^{\mathrm{a}}$ \\
Textura & $7,56 \pm 2,43^{\mathrm{a}}$ & $7,28 \pm 2,58^{\mathrm{a}}$ \\
Aceitação Global & $6,41 \pm 2,31^{\mathrm{a}}$ & $6,01 \pm 2,56^{\mathrm{a}}$ \\
\hline
\end{tabular}

Média \pm Desvio padrão; os valores com letras iguais, na mesma coluna, não diferiram estatisticamente entre si, ao nível de $5 \%$ de significância. Escala hedônica de dez pontos $(0=$ desgostei extremamente e 10 = gostei extremamente).

Boatto e colaboradores (2010) analisaram sensorialmente o queijo tipo petit-suisse de soja elaborado a partir da cultivar BRS 213, sendo que da escala de nove pontos utilizada, apresentou nota de 7,08 na aceitação global, valor que corresponde a um grau de aceitação "gostei regularmente" do queijo.

Observando a intenção de compra do queijo petit-suisse com extrato de soja sabor maracujá (Figura 3.3), parte dos provadores (46\%) "certamente" ou "provavelmente comprariam" o produto, e para o queijo petit-suisse com extrato de soja sabor morango, 38\% "certamente" ou "provavelmente" comprariam o mesmo. Os queijos tiveram baixa rejeição, pois somente $4 \%$ e $8 \%$ das pessoas "certamente não comprariam" os queijos petit-suisse com extrato de soja sabor maracujá e morango, respectivamente.

Entre os provadores que responderam que consomem eventualmente ou mensalmente $(68 \%)$ o queijo petit-suisse de base láctea, para o petit-suisse com extrato de soja sabor maracujá, observou-se que $30 \%$ dos provadores "certamente" ou "provavelmente" comprariam o produto, e apenas $2 \%$ dos provadores disseram que não comprariam o produto. Para a formulação com morango, notou-se que, dentre os que consomem eventualmente ou mensalmente o produto de base láctea (66\%), 30\% dos provadores "certamente" ou "provavelmente" 
comprariam o produto queijo petit-suisse com extrato de soja e apenas $4 \%$ disseram que não comprariam o produto.

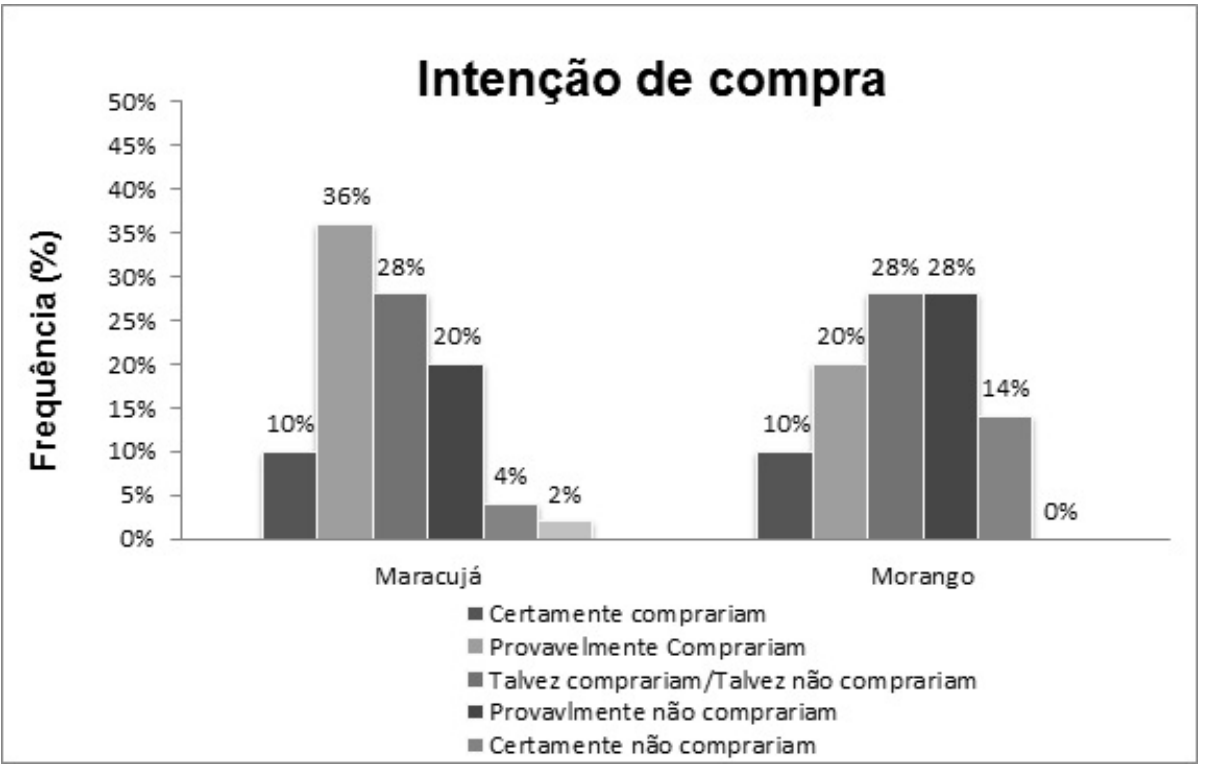

Figura 3.3 Intenção de compra dos queijos petit-suisse, com extrato de soja, sabores maracujá e morango

\section{CONCLUSÃO}

Após vários testes de formulações, obtiveram-se as melhores condições para a seguinte elaboração de petit-suisse com extrato de soja sabor maracujá e morango: $66,33 \%$ de coágulo, $20 \%$ de polpa de fruta, 13,33\% de açúcar cristal, 0,08\% de corante artificial, $0,06 \%$ de aroma artificial e $0,2 \%$ de goma guar e xantana.

As amostras não apresentaram diferenças significativas nas determinações de cinzas e lipídios. Nas análises de $\mathrm{pH}$ e acidez, as amostras de queijo petit-suisse com extrato de soja e as polpas de frutas diferiram entre si estatisticamente devido à composição das polpas de frutas. Os queijos e as polpas de maracujá apresentaram menores $\mathrm{pH}$ e elevada acidez se comparadas ao queijo petit-suisse com extrato de soja sabor morango. Nos atributos sensoriais, o sabor, a textura e a aceitação global das amostras não diferiram entre si. Os dois queijos elaborados com extrato de soja foram bem aceitos pelos provadores, sendo constatados pela avaliação de aceitação global, no qual os provadores "gostaram ligeiramente" do produto. Além disso, a formulação sabor maracujá foi a mais aprovada pelos provadores por meio da análise de intenção de compra, em que a maioria dos provadores "certamente" ou "provavelmente" compraria o queijo. 


\section{REFERÊNCIAS}

ACUÑA, S. P. C.; GONZÁLEZ, J. H. G.; TORRES, I. D. A. Physicochemical characteristics and functional properties of vitabosa (mucuna deeringiana) and soybean (glycine max). Ciênc. Tecnol. Aliment., Campinas, v. 32, n. 1, p. 98-105, jan.-mar. 2012. AOAC INTERNATIONAL. Official Methods of Analysis. 16. ed. Arlington: AOAC International, 1995. v.1-2.

BAVIA, A. C. F. et al. Chemical composition of tempeh from soybean cultivars specially developed for human consumption. Ciênc. Tecnol. Aliment., Campinas, v. 32, n. 3, p. 613-620, jul.-set. 2012.

BEHRENS, J. H.; SILVA, M. A. A. P. Atitude do consumidor em relação à soja e produtos derivados. Ciênc. Tecnol. Aliment.,Campinas, v. 24, n. 3, p. 431-439, jul.-set. 2004.

BEDANI, R. et al. Consumo de soja e seus produtos derivados na cidade de AraraquaraSP: um estudo de caso. Alim. Nutr., Araraquara, v. 18, n. 1, p. 27-34, jan.-mar. 2007.

BENASSI, V. T.; YAMASHITA, F.; PRUDÊNCIO, S. H. A statistical approach to define some tofu processing conditions. Ciênc. Tecnol. Aliment., Campinas, v. 31, n. 4, p. 897904, out./dez. 2011.

BOATTO, D. A. et al. Desenvolvimento e caracterização de queijo tipo petit-suisse de soja comum e de soja livre de lipoxigenase, enriquecidos com cálcio. Ciênc. Tecnol.

Aliment., Campinas, v. 30, n. 3, p. 766- 770, jul.-set. 2010.

BRASIL. Ministério da Agricultura, Pecuária e Abastecimento. Instrução Normativa n ${ }^{\circ} 1$ de 7 janeiro de 2000. Regulamento técnico geral para fixação dos padrões de Identidade e qualidade para polpa de fruta. Diário Oficial da União, Brasília, DF, 7 jan. 2000.

. Ministério da Agricultura, Pecuária e Abastecimento. Instrução Normativa ${ }^{\circ}$ 53 de 29 de dezembro de 2000. Regulamento Técnico de Identidade e Qualidade de Queijo “Petit-suisse”. Diário Oficial da União, Brasília, DF, 4. jan. 2001.

- Ministério da Saúde. Resolução RDC no 91 de 18 de outubro de 2000.

Regulamento técnico para fixação de identidade e qualidade de alimento com soja.

Diário Oficial da União, Brasília, DF, 20 out. 2000.

BORDINGNON, J. R.; MANDARINO, J. M. G. Soja: composição química, valor nutricional e sabor. Londrina: Embrapa, 1994.

CARDARELLI, H. R. et al. Inulin and oligofructose improve sensory quality and increase the probiotic viable count in potentially synbiotic petit-suisse cheese. Elsevier, São Paulo, n. 41, p.1037-1046, jul. 2008.

CARRÃO-PANIZZI, M. C. Valor nutritivo da soja e potencial de utilização na dieta brasileira. Londrina: Embrapa, 1988.

CARRÃO-PANIZZI, M. C.; MANDARINO, J. M. G. Soja: potencial de uso na dieta brasileira. Londrina: Embrapa, 1998.

CIABOTTI, S. et al. Avaliações químicas e bioquímicas dos grãos, extratos e tofus de soja comum e de soja livre de lipoxigenase. Ciênc. Agrotec., Lavras, v. 30, n. 5, p. 920 929, set.-out. 2006. 
CONAB - Companhia Nacional de Abastecimento. Acompanhamento de safra brasileira: grãos, quarto levantamento, janeiro 2016. Brasília: Conab. Disponível em: <http://www.conab.gov.br/OlalaCMS/uploads/arquivos/16_01_12_14_17_16_boletim_ graos_janeiro_2016.pdf>. Acesso em: 1 fev. 2016.

CUI, S. W. Food carbohydrates: chemistry, physical properties and applications. Boca Raton: CRC Press, 2005.

FELBERG, I.; ANTONIASSI, R.; DELIZA, R. Manual de produção de extrato de soja para agroindústria de pequeno porte. Rio de Janeiro: Embrapa Agroindústria de Alimentos, 2005.

FIB. Estabilizantes. Food Ingredients Brasil. n. 14, 2010. Disponível em: <http://www. revista-fi.com/materias/145.pdf>; Acesso em: 1 nov. 102014.

GUERREIRO, L. Dossiê Técnico: Produtos de Soja. REDETEC: Rede de Tecnologia do Rio de Janeiro, 2006.

HOUAISS, A.; VILLAR, M. S.; FRANCO, F. M. M. Dicionário Houaiss da Língua Portuguesa. Rio de Janeiro: Objetiva, 2001.

INSTITUTO ADOLFO LUTZ. Normas Analíticas do Instituto Adolfo Lutz: Métodos químicos e físicos para análise de alimentos. 4. ed. São Paulo: IMESP, 2008.

INSUMOS. As grandes gomas - Aditivos e ingredientes. São Paulo: Insumos. Disponível em: <http://www.insumos.com.br/aditivos_e_ingredientes/materias/297.pdf> . Acesso em 01 nov. 2014.

Hidrocolóides - Aditivos e ingredientes. São Paulo: Insumos. Disponível em: <http://www.insumos.com.br/aditivos_e_ingredientes/materias/297.pdf>. Acesso em 01 nov. 2014.

KUSKOSKI, E. M. et al. Frutas tropicais silvestres e polpas de frutas congeladas: atividade antioxidante, polifenóis e antocianinas. Ciênc. Rural, Santa Maria, v. 36, n. 4, p.1283-1287, jul.-ago., 2006.

MAIA, M. J. L.; ROSSI, E. A.; CARVALHO, M. R. B. Qualidade e rendimento do "leite" de soja da unidade de produção de derivados da soja - UNISOJA - FCF-Ar/ UNESP. Alim. Nutr., Araraquara. v. 17, n. 1, p. 65-72, jan.-mar. 2006.

MARUYAMA, L.Y. et al. Textura instrumental de queijo petit-suisse potencialmente probiótico: influência de diferentes combinações de gomas. Ciênc. Tecnol. Aliment., Campinas, v. 26, n. 2, p. 386-393, abr.-jun. 2006.

MATIAS, N. S. Desenvolvimento de alimento probiótico à base de soja com polpa de fruta. 2011. 78 f. Dissertação (Mestrado em Ciências) - Faculdade de Ciências Farmacêuticas, Universidade de São Paulo, São Paulo, 2011.

MISSÃO, M. R. Soja: origem, classificação, utilização e uma visão abrangente do mercado. Revista de Ciências Empresariais, v. 3, n. 1, p. 7-15, jan.-jun. 2006.

MOREIRA, R. W. M. et al. Avaliação sensorial e reológica de uma bebida achocolatada elaborada a partir de extrato hidrossolúvel de soja e soro de queijo. Acta Scientiarum, Maringá, v. 32, n. 4, p. 435-438, 2010. 
OLIVEIRA, T. A. et al. Avaliação da qualidade físico-química de polpas de frutas congeladas na cidade de Mossoró-RN. Revista Verde Mossoró-RN - Brasil, v. 9, n. 2, p. 248-255, abr-jun, 2014.

PRUDENCIO, I. D. et al. Petit-suisse manufactured with cheese whey retentate and application of betalains and anthocyanins. Elsevier, Florianópolis, n. 41, p. 905-910, mai. 2008.

RIBEIRO, K M. et al. Comportamento de cepas distintas de Lactobacillus acidophilus em queijo petit-suisse. Archivos Latinoamericanos de Nutricíon, v. 64, n. 4, p. 347-354, dez. 2012.

ROSSI, E. A; ROSSI, P. R. Bebidas funcionais à base de soja. In: VENTURINI FILHO, W. G. Bebidas não alcoólicas: Ciência e Tecnologia. 1.ed. São Paulo: Edgard Blucher, 2010. p. 57-79.

SCHORSCH, C.; GARNIER, C.; DOUBLIER, J.. Microscopy of xanthan/ galactomannan mixtures. Elsevier, Nantes, v. 28, n. 4, p. 319-323, dez. 1995.

STATSOFT, INC. (2011). STATISTICA (data analysis software system), version 10 . Www.statsoft.com.

SILVA, N. A. et al. Estudo de parâmetros físico-químicos de qualidade para polpas de acerola, abacaxi e maracujá. FAZU em Revista, Uberaba, n. 8, p. 89-94, 2011.

VEIGA, P. G.; VIOTTO, W. H. Fabricação de queijo petit-suisse por ultrafiltração de leite coagulado, efeito do tratamento térmico do leite no desempenho da membrana.

Ciênc. Tecnol. Aliment., Campinas, v. 21, n. 3, p. 267-272, set.-dez. 2001.

VEIGA, P. G. et al. Caracterização química, reológica e aceitação sensorial do queijo petitsuissebrasileiro. Ciênc. Tecnol. Aliment., Campinas, v. 20, n. 3, p. 349-357, set.-dez. 2000.

VIDAL, A. M. et al. A ingestão de alimentos funcionais e sua contribuição para a diminuição da incidência de doenças. Cadernos de Graduação - Ciências Biológicas e da Saúde, Aracaju, v. 1, n. 15, p. 43-52, out. 2012.

VIEIRA, L. C. et al. Extrato hidrossolúvel de soja (leite de soja) com sabores de frutas da Amazônia. Belém: EMBRAPA-CPATU, 1994.

VILlANUEVA, N. D. M.; PETENATE, A. J.; DA SILVA, M. A. A. P. Performance of the hybrid hedonic scale as compared to the traditional hedonic, self-adjusting and ranking scales. Food Quality and Preference. v. 16. p. 691-703, Issue 8, dez. 2005.

XUEWU, Z.et al. Rheological Models for Xanthan Gum. Elsevier, China, v. 27, n. 2, p. 203-209, dec. 1994. 
